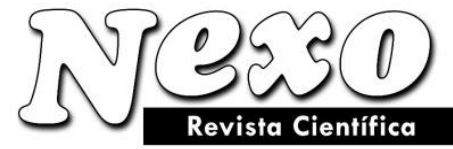

Vol. 34, No. 01, pp. 168-185/Marzo 2021
ISSN-E 1995-9516

Universidad Nacional de Ingeniería COPYRIGHT @ (UNI). TODOS LOS DERECHOS RESERVADOS http://revistas.uni.edu.ni/index.php/Nexo https://doi.org/10.5377/nexo.v34i01.11295

\title{
Design and development of a model and optimal planning for supply chain responsibility towards the environment
}

\section{Diseño y desarrollo de un modelo y planificación óptima para la responsabilidad de la cadena de suministro con el medio ambiente}

\author{
Shahram Mokhlesabadi ${ }^{1}$, Mohammad Reza Kabaranzad Ghadim ${ }^{2 *}$, Hasan Ali Aghajani \\ Kasegari $^{3}$, Mohammad Mahdi Movahedi ${ }^{1}$ \\ ${ }^{1}$ Department of Industrial Management, College of Management, Firoozkooh Branch, Islamic \\ Azad University, Tehran, Iran \\ ${ }^{2}$ Department of Management, College of Management \& Accounting, Central Tehran Branch, \\ Islamic Azad University, Tehran, Iran \\ ${ }^{3}$ Department of Industrial Management, Faculty of Economics and Administrative Sciences, \\ Mazandaran University, Sari, Iran \\ *kabaranzad@yahoo.com
}

(recibido/received: 01-December-2020; aceptado/accepted: 15-February-2021)

\begin{abstract}
The responsible management of product return flows in production and inventory environments is a rapidly increasing requirement for companies. This can be attributed to economic, environmental and/or regulatory motivations. Mathematical modeling of such systems has assisted decision-making processes and provided a better understanding of the behavior of such production and inventory environments. This paper reviews the literature on the modeling of reverse logistics inventory systems based on the economic order/production quantity (EOQ/EPQ) and the joint economic lot size (JELS) settings to systematically analyze the mathematics involved in capturing the main characteristics of related processes. The literature is surveyed and classified according to the specific issues faced and modeling assumptions. Special attention is given to environmental issues. There are indications of the need for reverse logistics models' mathematics to follow current trends in 'greening' inventory and supply-chain models. The modeling of waste disposal, greenhouse-gas emissions, and energy consumption during production is considered as the most pressing priority for the future of reverse logistics models. An illustrative example for modeling reverse logistics inventory models with environmental implications is presented .
\end{abstract}

Keywords: Reverse logistics, inventory, greenhouse-gas emissions, energy consumption, sustainability 


\section{RESUMEN}

La gestión responsable de los flujos de retorno de productos en entornos de producción e inventario es un requisito cada vez mayor para las empresas. Esto puede atribuirse a motivaciones económicas, ambientale $\mathrm{s}$ y / o regulatorias. El modelado matemático de tales sistemas ha ayudado a los procesos de toma de decis iones y ha proporcionado una mejor comprensión del comportamiento de dichos entornos de producción e inventario. Este artículo revisa la literatura sobre el modelado de sistemas de inventario de logística invers a que se basan en la orden económica / cantidad de producción (EOQ / EPQ) y la configuración del tamañ o de lote económico conjunto (JELS) para analizar sistemáticamente las matemáticas involucradas en la c aptura de las principales características de los procesos relacionados. La literatura se examina y clasifica d e acuerdo con los problemas específicos que se enfrentan y los supuestos del modelo. Se presta especial at ención a las cuestiones ambientales. Hay indicios de la necesidad de que las matemáticas de los modelos de logística inversa sigan las tendencias actuales en los modelos de cadena de suministro y inventario "ec ológicos". La modelización de la eliminación de residuos, las emisiones de gases de efecto invernadero y el consumo de energía durante la producción se considera la prioridad más urgente para el futuro de los $\mathrm{m}$ odelos de logística inversa. Se presenta un ejemplo ilustrativo para modelar modelos de inventario de logí stica inversa con implicaciones ambientales.

Palabras clave: logística inversa, inventario, emisiones de gases de efecto invernadero, consumo de energía, sostenibilidad.

\section{INTRODUCTION}

The concept of reverse logistics is not new. The reuse of products, components, and materials have been previously applied, mainly for the economic benefits of reusing the product or material instead of its disposal (Fleischmann et al., 1997). In addition to economic motivations, environmental concerns have directed the increase in the development of reverse logistics activities. Moreover, government pressure and legislation have contributed to the increased motivation for global environmental awareness and sustainability, influencing green supply chain management principles and practices (Sheu \& Chen, 2012). One such approach is the Extended Product Responsibility (EPR) legislation, which concentrates on the life-cycle and environmental performance of products (Subramanian et al., 2009) and fundamentally holds producers physically and financially responsible for the environmental impact of their products after their life has reached an end (Atasu \& van Wassenhove, 2012). Concerns regarding declining landfill sites, depletion of resources, and damage to the ozone layer, along with environmental legislation, have led to the developments required for prolonging product life, recycling, and reducing greenhouse gas (GHG) emissions (Bei \& Linyan, 2005; Gülsün et al., 2006; Bonney \& Jaber, 2011). A traditional forward supply chain involves the acquisition of raw material, production, and distribution of materials and products to end consumers. By contrast, reverse logistics is the opposite. It involves the collection, inspection, disassembly, reprocessing, redistribution and reuse of used products, and the disposal of associated wastes (Bei \& Linyan, 2005). A closed-loop supply chain integrates and coordinates the forward and reverse supply chain activities (Bei \& Linyan, 2005; Guide et al., 2003). As a result of an increase in environmental issues, green supply chains have emerged (both forward and closed-loop supply chains). The underlying difference between green supply chains and reverse logistics and/or closed-loop supply chains is that green supply chains account for environmental issues while reverse logistics and closed loop supply chains focus on the economic benefits of product recovery options (Bei \& Linyan, 2005; de Brito \& Dekker, 2003).

As the concern for managing product return flow increases due to both economic and/or environmental motivations, many authors have proposed quantitative models to study and analyze reverse logistics. Most 
of the mathematical modeling studies of reverse logistics have been focused on deterministic methods with limited research considering stochastic demand for repaired or recovered products (Pokharel \& Mutha, 2009). This paper studies the literature about the mathematical modeling of reverse logistics inventory models based on the economic order quantity (EOQ) and the joint economic lot size (JELS) settings to review and analyze the mathematics involved in capturing the associated processes. The literature is surveyed and classified according to content-related issues and modeling assumptions. The paper is organized as follows: a literature review is presented, followed by a review of mathematical models and a discussion summarizing what has been achieved and what needs to be done with an emphasis on environmental concerns. The paper concludes with some findings and outlines future research directions .

\section{LITERATURE REVIEW}

Quantitative inventory models and closed-loop supply chains can be classified under three main categories: distribution planning, inventory control, and production planning (Fleischmann et al., 1997). This paper focuses on the mathematical modeling of inventory with return flows that were developed in EOQ and JELS settings. The inventory management models' general objective is to control product orders, inventory levels, and recovery processes to guarantee a specific service level and minimize total costs. This paper provides a review of the studies that provided mathematical models that cite and extend the work of Schrady (Schrady, 1967), which is believed to be the first to trigger this line of research (Fleischmann et al., 1997). The research papers are classified based on content-related issues and modeling assumptions .

Inventory models are classified as either (a) single or multi-echelon, (b) deterministic or stochastic, and (c) one-for-one or batch repair and replenishment (Guide and Srivastava, 1997). There are different solution tools and techniques (single and multi-objective linear, integer, non-linear, and mixed-integer programming) that can be used to solve the various content-related issues, including inventory models, reverse distribution, and product recovery activities (Sasikumar and Kannan, 2009). Reverse logistics networks can be classified as directly reusable, remanufacturing, repair service, and recycling networks (Bostel et al., 2005). This classification basically depends on the type of product considered. Recovery activities include product, components/parts, material, and energy recovery (De Brito \& Dekker, 2003) The demand and return processes presented in the literature could be dependent, independent of each other, or dependent on price and quality, and are assumed as a continuous constant rate, a continuous dynamic rate, an arbitrary function of time, or not explicitly modeled (De Brito \& Dekker, 2003; Singh \& Saxena, 2012). Further, the demand and return rates could be assumed deterministic where all model parameters are known throughout the planning horizon or stochastic, which accounts for uncertainty. Another important characteristic of 'return flow' inventory systems is the number of stock points and stock inventory type (Akçalı \& Cetinkaya, 2011). These stock points can be classified as manufactured items, remanufactured items, combined manufactured and remanufactured items, new material items, and used item inventory (Akçalı \& Cetinkaya, 2011). From this classification, it is clear that the remanufactured items' quality is either assumed as-good-as-new or less than the newly produced items. The management of quality for different items has also been investigated in the literature (El Saadany \& Jaber, 2010). In general, a typical remanufacturing environment can be distinguished by the motivation behind the product recovery, the type of item to be recovered, the form of recovery, the activities required for recovery, the agents performing the recovery process, and finally, the location of the recovery activities (Akçalı \& Cetinkaya, 2011). Repair shops can either be in-house or independent and if spare parts are considered, they can be ordered from the original equipment manufacturer (OEM), or they can be repaired (Kleber et al., 2011). 
Using the various classification and categorization from the aforementioned literature, the research papers regarding the modeling of inventory management of reverse logistics can be identified under the following categories and sub-categories:

\subsection{Type of Model}

- $\quad$ EOQ, optimal, optimal quadratic, simulation, linear programming,

- $\quad$, mixed integer programming

- $\quad$ Single objective, multi-objective

- $\quad$ Deterministic, stochastic

- $\quad$ Number of decision variables

- $\quad$ Decision variable (batch quantity, production rate, number of batches)

Inventory Stock

Number of stock points (single-stock, two-stock, three-stock, and multi-stock points)

Types of stock points (new/raw material, manufactured item, used item remanufactured item, manufactured and remanufactured item inventories)

\section{Recovery Process}

Recovery activities (collection, inspection, separation, and disassembly)

- Form of recovery

- $\quad$ Product recovery (repair, refurbishment, reuse, remanufacturing, and repair)

- Material recovery (recycling)

- Component recovery (remanufacturing)

- $\quad$ Energy recovery

- Location of recovery activity (existing and/or separate facilities)

\subsection{Modeling Assumptions}

Demand rate (not considering, constant, price sensitive, arbitrary function of time)

- Production rate (not considering, constant, demand-dependant, arbitrary function of time)

- Return rate (not considering, constant, demand-dependant, price and quality dependant, arbitrary function of time)

- Remanufacturing/repair rate (not considering, constant, demand-dependant, arbitrary function of time)

- $\quad$ Quality of the remanufactured items (as-good-as-new, different from newly produced)

- $\quad$ Shortages (allowed/not-allowed)

- Used item repair and replenishment (one-for-one repair and replenishment, batch repair and replenishment)

- $\quad$ Number of times allowed to recycle

- $\quad$ Number of times allowed to reuse

- $\quad$ Single/multi-item products

- $\quad$ Spare parts/components (purchased new from OEM, repaired

- $\quad$ Product/component obsolescence

. Environmental Factors

- Greenhouse-gas (carbon) emissions

- $\quad$ Other air emissions

- $\quad$ Energy consumption/use

- $\quad$ Scrapping (solid waste)

- $\quad$ Biodegradability

- $\quad$ Noise

- $\quad$ Chemical waste 


$\begin{array}{ll}- & \text { Water usage } \\ - & \text { Toxic/hazardous waste } \\ \text { - } & \text { Fuel consumption } \\ \text { - } & \text { Thermal pollution }\end{array}$

The review of Sasikumar and Kannan (2009) highlighted the rising consciousness of stakeholders (managers, legislative bodies, customers, etc.) of environmental concern and how this has increased attention to reverse supply chains. They provided a comprehensive review of the literature to present two classification schemes and suggest research potential for reverse supply chains. Agrawal et al. (2015) further reinforced the finding of Sasikumar and Kannan (2009) regarding the rise in importance of reverse logistics attributed to growing environmental concerns and government pressures and sustainability issues. In their conclusions, Agrawal et al. (2015) drew attention to the "well-defined" costs and systems in forwarding logistics that are often not suitable for managing reverse flows of products. Similar to previous studies, Agrawal et al. (2015) provided classification and categories to suggest further research directions. Govindan et al. (2015) extended their review to include closed-loop supply chain models. Similar to (Sasikumar \& Kannan, 2009; Agrawal et al., 2015), they concluded that mathematical models for reverse logistics and closed-loop supply chain models should apply more environmental and sustainable objectives. Brandenburg et al. (2014) also discussed that the modeling of reverse logistics and closed-loop supply chains lacks investigation and development in comparison to forward supply chains, where they wrote: "the understanding and review of mathematical models that focus on environmental or social factors" (Brandenburg et al., 2014), which serves the purpose of this paper. Further, Brandenburg et al. (2014) discussed the scarcity of specific industry-focused studies that should not be overlooked, highlighting carbon emissions,energy and materials usage in transportation industries, such as hazardous waste management in chemical or pharmaceutical companies .

There is sufficient research on reverse logistic models; however, a review of the mathematics of inventory models in reverse logistics is not available in the literature. This paper discusses how the evolution of the mathematics of such models evolved since the work of Schrady (1967) and highlights future research trends that the authors think should be addressed with specific emphasis on environmental concerns

\section{QUANTITATIVE REVERSE LOGISTICS (RL) INVENTORY MODELS}

\subsection{Review methodology}

Content analysis can be argued as a tool for carrying out literature reviews in an organized and transparent manner (Seuring and Gold, 2012). Drawing on the recommendations of Seuring and Gold (2012), the review analysis follows these four steps: material collection, descriptive analysis, category selection, and material evaluation.

As mentioned in Section 2, the first reverse logistics model was developed by Schrady (1967) in 1967 (Fleischmann et al., 1997). The papers reviewed in this study are bound by their need to cite Schrady's (1967) work, be in the English language, peer-reviewed, and present a mathematical model. All papers citing Schrady (1967) up to August 2014, just before submitting this paper for review, have been considered to avoid bias. These papers have been surveyed using the 'Google Scholar' search engine. Each article has been reviewed individually to determine if it meets the aforementioned criteria. Corresponding to the research questions of whether reverse logistics mathematical models target environmental factors in their modeling, the following categories (keywords) have been derived inductively from the literature presented in Section 2: "environmental", "carbon emission", "GHG emissions", "greenhouse", "emissions", "green", "fuel", and "energy". For further analysis, an additional 5th criterion is added to limit the papers that extended Schrady's (1967) work to those whose mathematics 
is developed in EOQ and JELS settings. The models in these papers are then reviewed to develop insights and suggestions for future research. A summary of the adopted approach is presented in Figure 1.

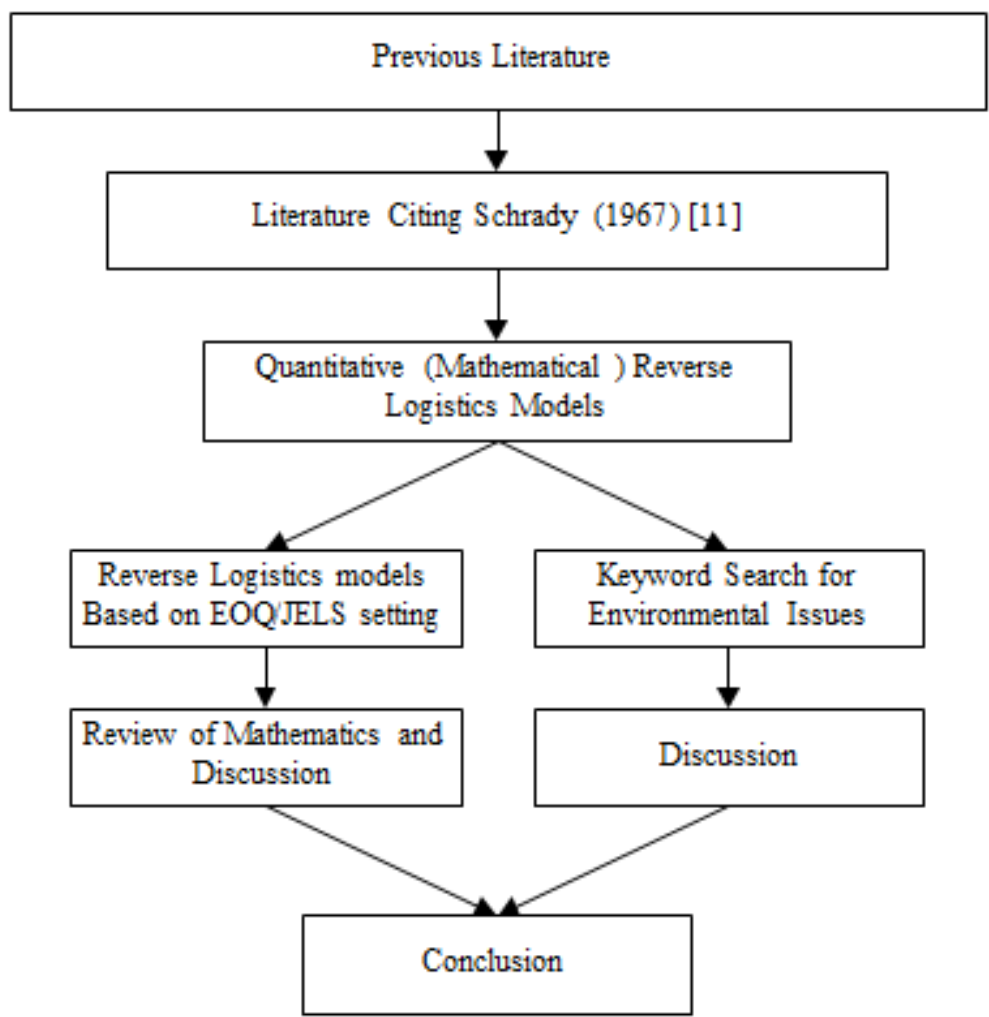

Figure 1. Framework for the study

\subsection{Literature review of quantitative RL inventory models}

The importance of repairing and recovering inventory was documented by Schrady (1967) back in the 1960s. A brief survey using the 'Google Scholar' search engine showed that (up to August 2014) there are 310 research papers that cite Schrady (1967) work, of which 183 that mathematically models inventory in a reverse logistics context. By focusing on the core papers, as seen by the authors, the next section portrays and discusses the evolution of the selected literature's mathematics. A survey of the 183 papers shows that none of these models considered the environmental effects of product recovery activities. A quick search for the word "environmental" appears in 87 of the 183 papers. A more specific search shows that the words "carbon emission" and "GHG emissions" do not appear at all. There is one instance for the word "greenhouse", 12 instances for the word "emissions," and 40 for the word "green". The word "fuel" occurred in 6 documents, and energy appeared in 24 papers. The majority of the surveyed papers mention these environmental keywords but do not consider them in their mathematical models. Some only have these keywords appear in their lists of references, and some have them appear in a context that is not relevant to the inventory scope (e.g., part of the product design or modeling an inventory system in the context of an exergy system). Those who have the environmental consideration in the modeling are limited to including the environmental factor as part of many components of the unit production cost or combined environmental/quality factor.

The work of Schrady (1967) can be considered the corner-stone for inventory models that are based on the EOQ and JELS in a reverse-logistics setting. The core mathematical modeling extensions of (1967), as seen by the authors, are the works of Richter and Teunter and later amalgamated by El Saldana. These 
works, whether written individually or in collaboration with other authors, have been selected based on the relevant content proposed in each of their research material. Figure 2 summarizes the evolution of research by these authors.

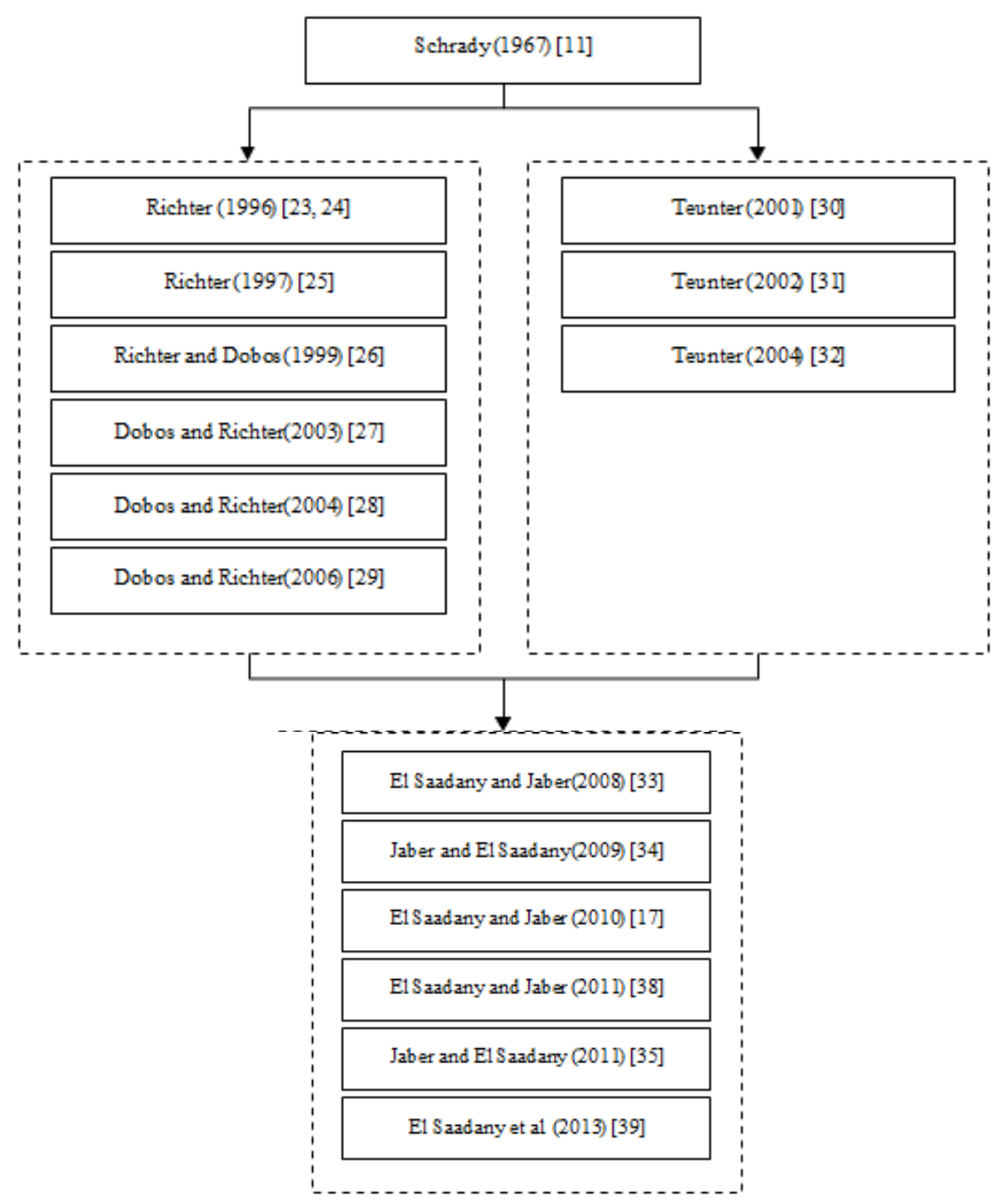

Figure 2. The three clusters of reverse logistics model based on EOQ/JELS setting

Schrady (1967) proposed an EOQ model considering the repair of items with manufacturing and recovery rates. Richter (1996) assumed that collected items may or may not be recoverable, which is different from the assumption adopted by Schrady (1967), who assumed a continuous flow of used items returning to the manufacturer. This assumption by Richter (1996) implies that some items may be disposed of as waste. Richter (1997) and Richter and Dobos (1999) extended the earlier work of Richter (1996) to show that a bang-bang policy of either no waste (i.e., all returned items are to be repaired) or no repair (i.e., all items are disposed of as waste) is optimal compared to a mixed policy. Dobos and Richter (2003) extended the models by assuming a finite production and repair rate. The model is then generalized in Dobos and Richter (2004) for multiple production and repair cycles. In a later paper, Dobos and Richter (2006) considered the returned items' quality and assumed that not all returned items could be reused. They further showed that a mixed policy of remanufacturing used items and producing new ones is better than a bang-bang policy, as suggested earlier . 
Like Richter, Teunter (2001) extended Schrady's (1967) work by assuming that unit holding costs for newly manufactured and remanufactured items are different and considered more than one production and repair cycle. Teunter (2002) considered stochastic demand and return rates and assumed no lead time. Discounted costs were also considered to make the model resemble more realistic situations. Teunter (2004) presented simplified closed-form expressions to determine the optimal lot-size quantities for the production or procurement of new items and the collection of used ones for recovery for finite or infinite production and recovery rates .

Focusing on the core papers as seen by the authors (those presented in Figure 2), the next section will portray and discuss the evolution of the mathematics for the literature presented.

\subsection{Review of the mathematics}

The following section selects specific models from those presented in Figure 2. Almost 30 years after Schrady (1967), Richter (1996) extended it by considering waste disposal, thus, being the first environmental issue to be modelled and analyzed mathematically. Teunter (2001) also generalized the work of Schrady (1967) and differentiated it from Richter (1996) by considering a variable disposal rate and different holding costs for manufactured and remanufactured items. Continuing along the Richter and Teunter clusters' lines, years later, El Saadany \& Jaber, (2008) provided another primary change in the assumptions that have considerable environmental implications. They discussed that materials and products could be repaired a limited number of times before a product either loses its characteristics or can no longer be repaired. This assumption is more realistic and has added a new shift in the modeling. It assumes that more waste is disposed of than has been accounted for in previous models. The following sections present a brief summary of the mathematics of the selected papers

\subsubsection{Schrady (1967)}

The model of Schrady (1967) determines the economic order quantities for procurement and repair batches in a simple system with two separate inventories, ready-for-issue (RFI) and non-ready-for-issue (NRFI)inventories where the NRFI items are repaired. Basic assumptions include a deterministic model that considers no backorders.

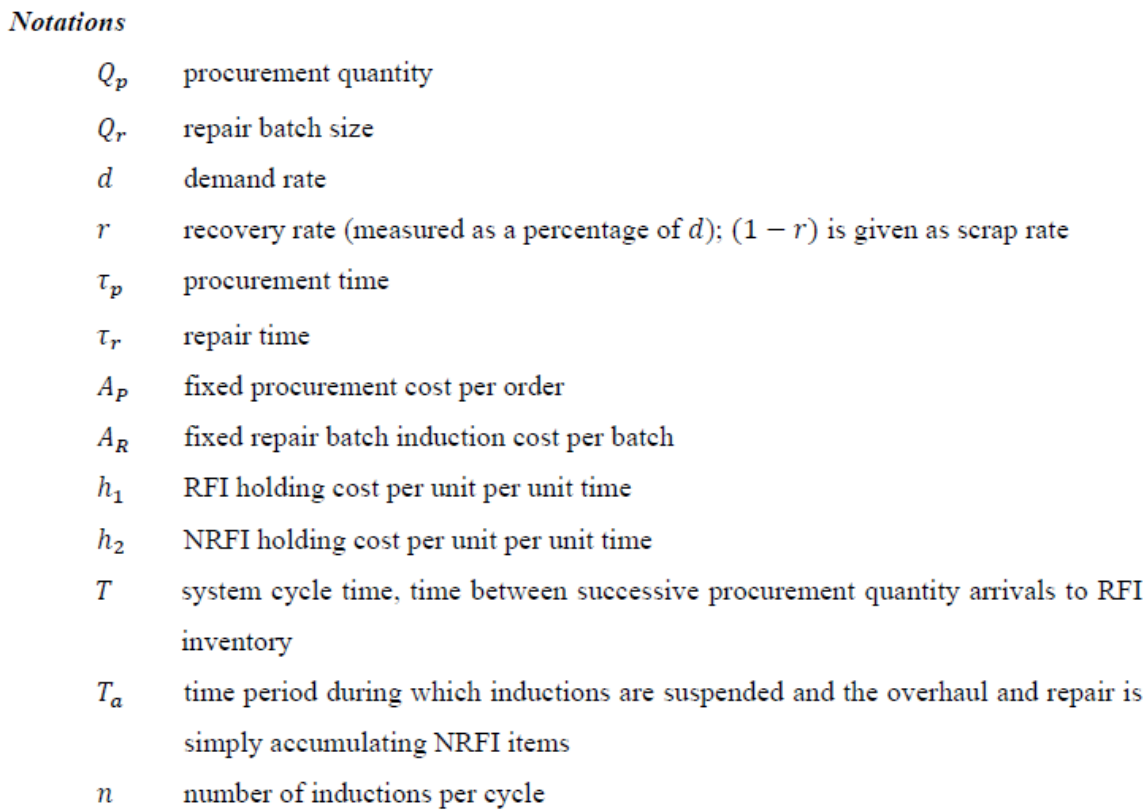




\subsection{Mathematical Model}

The number of orders per cycle is given by:

The cycle time is formulated as:

$$
\begin{gathered}
n=\left(\frac{r}{1-r}\right) \frac{Q_{P}}{Q_{R}} \\
T=\frac{Q_{P}}{(1-r) d}
\end{gathered}
$$

The total cost per cycle is given as the summation of the fixed order procurement cost multiplied by the number procurements per cycle (one in this case), the fixed induction cost multiplied by inductions per cycle, the holding cost of RFI inventory, and the holding cost of NRFI inventory. That is the total cost per cycle can be given as:

$$
T C_{\text {cycle }}=A_{P}+n A_{R}+h_{1} A_{1}+h_{2} A_{2}
$$

Dividing by the cycle time, the total cost per unit time is given as:

$$
T C=\frac{A_{P} d(1-r)}{Q_{P}}+\frac{A_{R} r d}{Q_{R}}+\frac{h_{1} r}{2}\left(Q_{R}+\left(\frac{1-r}{r}\right) Q_{P}\right)+\frac{h_{2} r}{2}\left(Q_{P}+Q_{R}\right)
$$

Differentiating the above equation with respect to the procurement quantity and repair batch size respectively, the optimal order quantities can be given as:

$$
Q_{P}^{*}=\sqrt{\frac{2 A_{P} d(1-r)}{h_{1}(1-r)+h_{2} r}} \text { and } Q_{R}^{*}=\sqrt{\frac{2 A_{R} d}{h_{1}+h_{2}}}
$$

It is clear that if the scrap rate is zero, i.e., then there is no need to procure new items by the system .

\section{DISCUSSION}

The complexity of the models and the mathematics has evolved with time and with the gradual relaxation of some assumptions. The objective of most of the models is to minimize the total cost of a system. The majority of the models do so by optimizing the order quantity or the batch size. However, some studies have different decision variables that include the number of production batches in a cycle, the number of repairs/remanufacture batches in a cycle and even price, or the purchase price and the accepted quality level of returned items. Also, based on the assumptions, the inventory stock points and types may vary with the recovery activities performed. Based on the classifications and categorizations presented in section 2, the models presented are summarized, highlighting the inventory stock points and recovery activities.

Throughout the three clusters, all models can be classified as single objective, linear models based on the EOQ model, except for El Saadany and (2010), which is a mixed-integer problem, and all are deterministic except for Teunter (2002). Although the paper of Schrady (1967) focuses on searching for 
procurement and repair batch quantities, the papers in the Teunter cluster focus on the manufacturing batch size, whereas the Richter cluster focuses on the production and remanufacturing/recycling lot sizes. The El Saadany cluster, however, considers several decision variables. All three clusters consider two stock points for used items, and a combined stock point for the manufactured and remanufactured items, with the exception of Dobos and Richter $(2003 ; 2004 ; 2006)$ where the two stock points considered are used items and manufactured items. The three clusters' papers consider collection and repair as the recovery activities with Dobos and Richter $(2003 ; 2004 ; 2006)$ and the El Saadany cluster adding a third activity, inspection. Jaber and El Saadany (2009) and El Saadany and Jaber (2008) extended the recovery activities to include remanufacturing, with the latter including disassembly where components and parts of a product are recovered as opposed to recovering a product as a whole (a simplistic assumption of the clustered and other models in the literature)

In general, the objectives of the various research problems are extensions of the classical EOQ inventory problem and revolve around determining the optimal batch size for production, the optimal batch size for repair/remanufacturing, and the number of production and repair/remanufacturing in a time interval to minimize the total costs of the system. The complexity of the models under the various assumptions discussed in the previous section has kept the mathematical models limited to two-inventory stock points: that of the first shop that produces 'serviceable' items ready for use, and that of the second shop that accumulates used items ready to be repaired or remanufactured. The terminology has been corrected for some of these works based on the definitions provided in El Saadany and Jaber (2008). For example, the work of Dobos and Richter (2003) uses the term recycling; however, recycling refers to recovering material, but what actually occurs in their model is the repairing of returned (used) items to a state where it is as-good-as new. Another example is the work of El Saadany and Jaber (2008), where disassembly is part of the process.

Numerous issues concerning the environment are present in a supply chain. From the literature reviewed in this study, it is evident that the only environmental concern is that of wasted product, and even this is only considered as a disposal cost. Many environmental factors may arise from the disposal of a product, including the use of landfills and the issue of biodegradability. Moreover, products consist of assemblies and components of which some could have liquids and/or gases that may be toxic or may contain other harmful materials.

A possible approach to modeling: From the above discussion, it becomes apparent that a model that can capture the environmental factors present in reverse logistic systems is becoming inevitable. A new approach to the modeling of reverse logistics is suggested herein. Previous attempts treat the problem as a traditional inventory problem even though environmental factors no longer make the problem a traditional one. This section seeks to present an example 'only' to illustrate the suggested approach: it merely formulates the problem, but there is no attempt to solve it. The solution to the problem is left for additional research.

The suggested approach attempts to minimize multiple objectives, including costs and individual environmental factors alike. For the case of this illustration, the following environmental factors are considered: GHG emissions from production, energy usage for production, and disposal of solid waste(unrepairable items). The concept of this model is based on the work of Richter (1996). We extend this model to include the assumption of El Saadany and jabber (2010) that an item can only be recovered a limited number of times. For simplicity, additions from the Teunter (2001) model to account for different holding costs and the possibility of variable disposal rates will not be considered in this illustration.

The rationale for the proposed approach is that the real costs of some environmental factors are difficult to estimate, e.g., the costs of polluting air, soil, and water tables to the public. As a result, the model is 
now presented as a multi-variable multi-objective non-linear mixed-integer programming problem. Such a problem can be considered a scalar function but can be attempted as a multi-objective optimization problem. Since there is no single point that will simultaneously optimize all objectives at once, two fundamental approaches can be suggested: (1) secularization and (2) Pareto. Not necessarily the most effective solution, one approach that is suggested in this paper for illustrative purposes and for its simplicity, is to have the objective function normalized as costs, GHG emissions, energy used, and items disposed of are of different units. The importance of each factor is determined by weight. Individual priorities for the costs and the environmental factors can be determined from the experience of managers, various stakeholders, and ultimately the decision-makers involved. This problem is not discussed in this paper but is rather left for future investigation.

The model considers three main cost categories: the EOQ related and non-related costs given in Eqs. (8) and (9), respectively, as presented by Richter (1997), as well as the investment cost associated with the repair and recovery of returned items given in Eq. (14). It should be remembered that El Saadany and jabber (2010) showed that the $\beta$ in Eqs. (8) and (9) has to be replaced with $\beta_{\zeta}$, where $\square$ is the number of time to recover an item, is given in Eq. (13).

The total number of items disposed of as solid waste by the system, $S_{w}$, is computed as:

$$
S_{w}=\alpha d
$$

Where the proportion of used units returned and disposed, , can be calculated as:

$$
\alpha=1-\beta_{\zeta}=(1-\beta)\left(\frac{1}{1-\beta^{\zeta+1}}\right)
$$

From Jaber \& El Saadany, (2011) the emissions generated from a production process is given in terms of the production rate as:

$$
E=a_{6} P^{2}-b_{6} P+c_{e}
$$

$\because:$

E $\quad \mathrm{GHG}\left(\mathrm{CO}_{2}\right)$ emissions generated per year (ton/year)

$a_{e} \quad$ emissions function parameter (ton year $^{2} / \mathrm{unit}^{3}$ )

$b_{e} \quad$ emissions function parameter (ton $\cdot$ year/ $/$ unit $^{2}$ )

$c_{e} \quad$ emissions function parameter (ton/unit)

$P \quad$ production rate (units/year) 
From Kleber et al., (2010) we can deduce the average energy used for production activities as: (10)

$$
\begin{aligned}
& E_{M}=\left(\frac{W_{m}}{P_{h}}+k_{m}\right) d \\
& \text { Where: } \\
& E_{M} \quad \text { the amount of energy consumed per cycle }(\mathrm{kWh} / \mathrm{year}) \\
& W_{m} \quad \text { idle power of the production machine }(\mathrm{kW}) \\
& k_{m} \quad \text { energy required by the production machine to produce one unit }(\mathrm{kWh} / \mathrm{unit}) \\
& P_{h} \quad \text { production rate (units/hour), where } 1 \text { year }=300 \text { days } \mathrm{x} 8 \text { hours } / \text { day }=2400 \text { hours }
\end{aligned}
$$

It should be clearly taken note that one of the underlying assumptions in Richter (1996) is that they both assumed instantaneous replenishment of items. However, the GHG emissions and energy used presented in the models of Jaber \& El Saadany, (2011), are a function of the production rate; that is, they do not assume instantaneous replenishment. As this model is only for illustrative purposes (and for simplicity), the cost functions by Richter (1996) shall be used as is and the economic production quantity (EPQ) model will be used to find the production rate required for the GHG emissions and energy used functions. If there is an intention to solve the problem, then the mathematics involved in Richter (1996) must be revisited, relaxing the assumption of an instantaneous replenishment. In light of the aforementioned discussion, and given the EPQ model where it can be rearranged to show that:

$$
P=\frac{d}{1 \frac{25 d}{h x^{2}}}
$$

$$
\text { Where } 1-\frac{2 s d}{h x^{2}}>0
$$

The ideal objective function is now to minimize EOQ related and non-related costs, the remanufacturing investment cost, the GHG emissions from production, the energy used for production, and the solid waste disposed of by the system. The minimization of each of these costs and the environmental factors may not necessarily be feasible, so the objective becomes to minimize an overall objective encompassing all the factors jointly. A number of methods exist that can be used to solve multi-objective optimization problems, including aggregating methods, population-based non-Pareto methods, and Pareto-based none elitist and elitist methods. For illustrative purposes and to keep the model relatively simple, a weighted sum method (an aggregate approach) is considered. Given the nature of the different units of measure involved, each factor must be normalized to formulate the objective function. Under traditional models and decision making supply chains are optimized in order to minimize EOQ-related costs. For this reason, the reference point to which all factors shall be normalized is the optimal policy for the decision variables, and that will yield a minimum value of the sum of the EOQ related costs. The non-related EOQ costs, the remanufacturing investment cost, the GHG emissions, energy used, and solid waste disposed are computed based on this policy. As a result, there is now a total costs reference, GHG emissions reference, and solid waste reference that can be used for the normalization of each factor. 
The model is considered two-fold: first is to minimize regarding EOQ related costs to obtain the reference points for normalization, and the second is to solve the costs and environmental-related factors combined collectively. That is, the first problem is:

$$
\begin{aligned}
& \min \{x, m, n, \zeta\} \\
& =\frac{\text { system total cost }}{\text { reference cost }} w_{1}+\frac{\text { GHG emissions }}{\text { reference emissions }} w_{2}+\frac{\text { energy used }}{\text { reference energy }} w_{3} \\
& +\frac{\text { solid waste }}{\text { reference waste }} w_{4}
\end{aligned}
$$

Where the priority weights are given to the summation of all costs, , the GHG emissions, , the energy for production, and the solid waste disposed of, .

Adding Eqs. (8), (9), and (14), replacing all with Eq. (13) and substituting with Eq. (18) the total system costs, TSC, can be written as

$$
\begin{aligned}
T S C=(m r+ & n s) \frac{d}{x} \\
& +\frac{x}{2}\left[h\left(\frac{\left(\frac{(1-\beta)}{1-\beta^{\zeta+1}}\right)^{2}}{n}+\frac{\left(1-\frac{(1-\beta)}{1-\beta^{\zeta+1}}\right)^{2}}{m}\right)+u\left(1-\frac{(1-\beta)}{1-\beta^{\zeta+1}}\right)\right. \\
& \left.+\frac{u\left(1-\frac{(1-\beta)}{1-\beta^{\zeta+1}}\right)^{2}(m-1)}{m}\right]+d\left[\frac{(1-\beta)}{1-\beta^{\zeta+1}}(b+e-k)+k\right] \\
& +c_{\text {Inv }}\left(1-e^{-\theta \zeta}\right)
\end{aligned}
$$

Similarly, the disposed units may be written as:

$$
\text { Solid waste }=\left(\frac{(1-\beta)}{1-\beta^{\zeta+1}}\right) d
$$

The determination of the priority weights and solving the above problem is beyond the scope of this paper. However, a brief numerical example is provided for illustrative purposes only. This paper does not seek to solve (optimize) this model for all decision variables but rather illustrate what the model may capture and how it may be used and further developed regarding the modeling of environmentally responsible inventory and reverse logistics models.

The first step is to obtain the reference values for each factor, which is done by determining a value that minimizes the EOQ related costs only. Doing so results in a value of. If this policy is now implemented in the multi-objective model, then a total score of 5 will be realized as each factor will have a value of 1 . The second step of the solution process is to apply the model to find a value that shall jointly minimize the overall objective based on the priorities set. The result shows a new value with an overall score of. Even though the result is jointly minimized, this policy shows an increase in cost by about $2.4 \%$ (from $\$ 72,413.75$ to $\$ 74,158.47$ ), but significant reductions in both GHG emissions of $41.1 \%$ (from 349.17 tons to 205.65 tons) and energy used for the production of $39.4 \%$ (from $185,549 \mathrm{kWh}$ to $112,496 \mathrm{kWh}$ ), with 
no change in the amount of solid waste. This result reflects the complexity of the given problem. There may be no solution that can minimize all individual factors simultaneously, and trade-offs are inevitable. Table 1 shows how the different objectives relate to one another and how some of the trade-offs may be present, depending on the focus of the problem. A double arrow represents a significant increase (if pointing up) or decreases (if pointing down).

For the one case where the focus is on minimizing GHG emissions, energy may increase or decrease. GHG emissions have a quadratic function with a local minimum where energy reduces exponentially as the production rate is increased. As a result, we have two cases: if the production rate is already high, i.e., beyond the minimum GHG point, then it must be reduced to achieve a minimum level of emissions, which will increase energy usage, whereas, if the production rate was too low, i.e., below the minimum GHG emissions point, then it will be increased to achieve minimum GHG emissions and thus increase energy usage. Table 1 rather simplifies some of the relationships, and further investigation is required for more in-depth analysis.

Table 1. General relationships between the different objectives

\begin{tabular}{|l|l|l|l|l|}
\hline Managerial Focus & Costs & $\begin{array}{l}\text { GHG } \\
\text { Emissions }\end{array}$ & Energy & $\begin{array}{l}\text { Disposal } \\
\text { Waste }\end{array}$ \\
\hline MIN Cost & $\downarrow \downarrow$ & $\uparrow$ & $\uparrow$ & $\uparrow$ \\
\hline MIN GHG emissions & $\uparrow$ & $\downarrow \downarrow$ & $\uparrow$ or $\downarrow$ & - \\
\hline MIN Energy & $\uparrow$ & $\uparrow$ & $\downarrow \downarrow$ & - \\
\hline MIN Disposal Waste & $\uparrow$ & $\uparrow$ & $\uparrow$ & $\downarrow \downarrow$ \\
\hline
\end{tabular}

\section{CONCLUSION}

This paper concentrated on reviewing the mathematics of reverse logistics models germinated from the seminal work of Schrady (1967), and has shown that the main focus of the mathematics after 60 years of modeling development is still mainly based on EOQ related costs and some recovery process costs. The surveyed studies' main decision variables include the production batch size, the remanufactured (recovered/repaired) batch size, and how many of each, respectively. The research's main direction for some studies was inclined to consider the quality of returned and remanufactured items, the number of times repaired items can be recovered, and the acquisition price of a returned item, with the return rate a price and quality dependent. It should be noted that this paper is not a review of the literature of reserves logistics where it summarizes briefly what generally has been done. For this purpose, readers may refer to two very recent reviews on the topic Agrawal et al. (2015) and Govindan et al. (2015), which neither reviewed the works along the line of Schrady (1967) nor touched on environmental issues such as GHG emissions, energy consumption, and landfill disposal.

To answer the question of what needs to be done, the authors of this paper showed that there are a gap and a need to incorporate the modeling of the environmental and societal issues in reverse logistics inventory models as they inevitably affect the decision variables associated with inventory and other policies. The incorporation of environmental factors translates the reverse logistic inventory models to being more sustainable and realistic as they become more representative of the real-world intricacy and sophistication. Current environmental issues of concern that have been modeled to some extent include waste disposal, GHG emissions, and energy usage. The amalgamation of the three in a more 
comprehensive context concerning reverse logistics inventory models has not been done or investigated (up to August 2014). Moreover, many managerial decisions in inventory models have environmental impacts, including the adoption of learning, leasing policies, quality improvement, design improvements, the disassembly of products, reusability, recyclability, biodegradability, coordination mechanisms, etc. Integrating environmental factors to reverse logistic modeling is seen as vital when considering environmental responsibility and sustainability of businesses and organizations.

Finally, it should be emphasized that this work may be further extended considering other issues, like legislative requirements or marketing aspects that may have a considerable impact on reverse logistics and, thus, may need to be incorporated in the mathematical modeling. While this manuscript was under review and in revision, a paper appeared that investigated an RL model (based on Richter, (1996)).

\section{REFERENCES}

Agrawal, S., Singh, R. K., \& Murtaza, Q. (2015). A literature review and perspectives in reverse logistics, Resour. Conservat. Recycl, 97, 76-92.

Akçal1, E., \& Cetinkaya, S. (2011). Quantitative models for inventory and production planning in closed-loop supply chains, Int. J. Prod. Res, 49(8), 2373-2407.

Atasu, A., \& van Wassenhove, L.N. (2012). An operations perspective on product take-back legislation for ewaste: Theory, practice, and research needs, Prod. Oper. Manag, 21-3, 407-422.

Bei, W., \& Linyan, S. (2005). A review of reverse logistics, Appl. Sci, 7, 16-29.

Bonney, M., \& Jaber, M.Y. (2011). Environmentally responsible inventory models: Non-classical models for a non-classical era, Int. J. Prod. Econ, 133(1), 43-53.

Bostel, N., Dejax, P., \& Lu, Z. (2005). The design, planning, and optimization of reverse logistics networks, in: Logistics systems: design and optimization, Springer US, 171-212.

Brandenburg, M., Govindan, K., Sarkis, J., \& Seuring, S. (2014). Quantitative models for sustainable supply chain management: Developments and directions. Eur. J. Oper. Res., 233(2), 299-312.

De Brito, M.P., \& Dekker, R. (2003). A Framework for Reverse Logistics. ERIM Report Series Research in Management, ERS-2003-045-LIS.

Dobos, I., \& Richter, K. (2003). A production/recycling model with stationary demand and return rates, Cent. Eur. J. Oper. Res, 11(1), 35-46.

Dobos, I., \& Richter, K. (2004). An extended production/recycling model with stationary demand and return rates, Int. J. Prod. Econ, 90(3), 311-323.

Dobos, I., \& Richter, K. (2006). A production/recycling model with quality consideration, Int. J. Prod. Econ, 104(2), 571-579.

El Saadany, A.M.A., \& Jaber, M.Y. (2008). The EOQ repair and waste disposal model with switching costs, Comput. Ind. Eng, 55(1), 219-233.

El Saadany, A.M.A., \& Jaber, M.Y. (2010). A production/remanufacturing inventory model with price and quality dependant return rate, Comput. Ind. Eng, 58(3), 352-362. 
Fleischmann, M., Bloemhof-Ruwaard, J.M., Dekker, R., van der Laan, E., van Nunen, J.A., \& van Wassenhove, L.N. (1997). Quantitative models for reverse logistics: a review. Eur. J. Oper. Res, 103(1), 1-17.

Govindan, K., Soleimani, H., \& Kannan, D. (2015). Reverse logistics and closed-loop supply chain: A comprehensive review to explore the future, Eur. J. Oper. Res, 240, 603-626.

Guide Jr, V. D. R., \& Srivastava, R. (1997). Repairable inventory theory: models and applications, Eur. J. Oper. Res, 102(1), 1-20.

Guide, V.D.R., Harrison, T.P., \& van Wassenhove, L.N. (2003). The challenge of closed-loop supply chains, Interfaces, 33(6), 3-6.

Gülsün, B., Bıyık, G., \& Özgen, D. (2006). Reverse logistics: A survey, 10th International Research/Expert Conference TMT 2006, Barcelona-Lloret de Mar, Spain, 11-15 September.

Jaber, M.Y., \& El Saadany, A. (2009). The production, remanufacture and waste disposal model with lost sales, Int. J. Prod. Econ, 120(1), 115-124.

Jaber, M.Y., \& El Saadany, A. (2011). An economic production and remanufacturing model with learning effects, Int. J. Prod. Econ, 131(1), 115-127.

Kleber, R., Zanoni, S., \& Zavanella, L. (2011). On how buyback and remanufacturing strategies affect the profitability of spare parts supply chains, Int. J. Prod. Econ, 133(1), 135-142.

Pokharel, S., \& Mutha, A. (2009). Perspectives in reverse logistics: a review, Resour. Conservat. Recycl, 53(4), 175-182.

Richter, K. (1996). The EOQ repair and waste disposal model with variable setup numbers, Eur. $J$. Oper. Res, 95(2), 313-324.

Richter, K. (1996). The extended EOQ repair and waste disposal model, Int. J. Prod. Econ, 45(1-3), 443-447.

Richter, K. (1997). Pure and mixed strategies for the EOQ repair and waste disposal problem. OR Spektrum, 19(2), 123-129.

Richter, K., \& Dobos, I. (1999). Analysis of the EOQ repair and waste disposal problem with integer setup numbers, Int. J. Prod. Econ, 59(1-3), 463-467.

Sasikumar, P., \& Kannan, G. (2009). Issues in reverse supply chain, part III: classification and simple analysis, Int. J. Sustain. Eng, 2(1), 2-27.

Schrady, D.A. (1967). A deterministic inventory model for reparable items, Nav. Res. Logist. Q, 14(3), 391-398.

Seuring, S., \& Gold, S. (2012). Conducting content analysis based literature reviews in supply chain management. Supply Chain Manage, 17(5), 544-555.

Sheu, J.B., \& Chen, Y.J. (2012). Impact of government financial intervention on competition among green supply chains, Int. J. Prod. Econ, 138(1), 201-213. 
Singh, S.R., \& Saxena, N. (2012). An optimal returned policy for a reverse logistics inventory model with backorders, Adv. Decis. Sci. Article ID 386598, 21 pages

Subramanian, R., Gupta, S., \& Talbot, B. (2009). Product design and supply chain coordination under extended producer responsibility, Prod. Oper. Manag, 18(3), 259-277.

Teunter, R.H. (2001). Economic order quantities for recoverable item inventory system, Nav. Res. Logist, 48(6), 484-495.

Teunter, R.H. (2002). Economic order quantities for stochastic discounted cost inventory system with remanufacturing, Int. J. Logist, 5(2), 161-175.

Teunter, R.H. (2004). Lot-sizing for inventory systems with product recovery, Comput. Ind. Eng, 46(3), 431-441.

\section{SEMBLANCE OF THE AUTHORS}

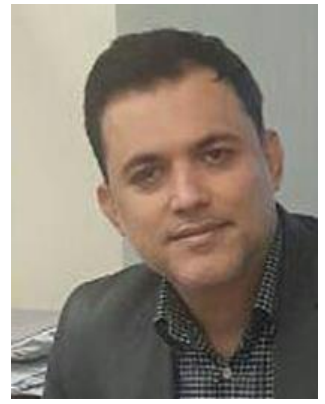

Shahram Mokhlesabadi is a Ph.D student, Faculty of Management, Firuzkuh Branch, Islamic Azad University, Tehran, Iran. Presently working as a Products Manager in Mellat Bank, Tehran, Iran. Presently trying to attend University to get his $\mathrm{PhD}$ in Industrial Management. He has attained professional experience of high quality doing lots of research projects on different aspects of Logistics management and Engineering. His research interests are principles of Logistics Optimization, Inventory Management, Business and Banking Management.

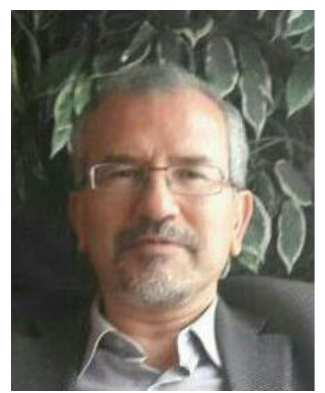

Mohammad Reza Kabaranzad Ghadim is Associated Professor, Faculty of Management, Central Tehran Branch, Islamic Azad University, Tehran, Iran. Presently working as an Associated Professor in Department of Management in Islamic Azad University, Central Tehran Branch. He has attained professional experience of high quality working with different groups of scholars in the field of management. His research interests are Logistics and Production Engineering and management, Entrepreneurship Management, Business and Marketing Management.

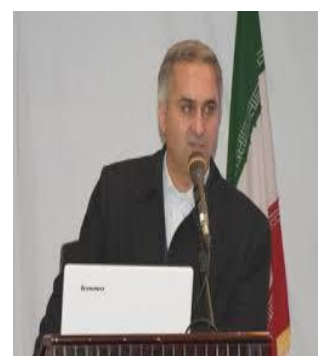

Hasan Ali Aghajani Kasegar is a Professor, Faculty of Management, Mazandaran University, Iran. Presently working as a Professor in Department of Management in Mazandaran University. He has attained professional experience of high quality working with different groups of scholars in the field of management. His research interests are in Logistics and Production Engineering and Management, Human Resource Management, Entrepreneurship Management, Business Management and Marketing. 


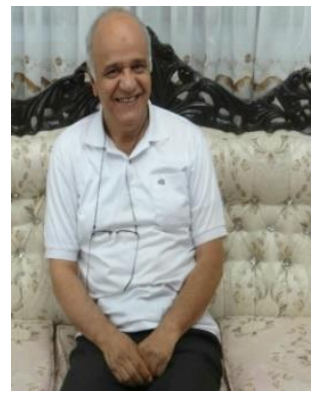

Mohammad Mahdi Movahedi is an Assistant Professor, Faculty of Management, Firuzkuh Branch, Islamic Azad University, Tehran, Iran. Presently working as Assistant Professor in Department of Industrial Management in Firuzkuh University. He has attained professional experience of high quality working with different groups of scholars in the field of management. His research interests are in Logistics and Production Engineering and Management, Maintenance, Business Management and Marketing. 